\title{
A Rare Case of Cervix Metastasis from a Breast Primary
}

\author{
Sajal Goel ${ }^{1 *}$, Pankaj Kumar Sharma ${ }^{2}$ and Mamta Lodha ${ }^{1}$ \\ ${ }^{1}$ Ex Senior Resident, Department of Clinical Oncology, Delhi State Cancer Institutes, India \\ ${ }^{2}$ Assistant Professor, Department of Radiology, Delhi State Cancer Institutes, India
}

Submission: September 28, 2020; Published: October 13, 2020

*Corresponding author: Sajal Goel, Ex Senior Resident, Department of Clinical Oncology, Delhi State Cancer Institutes (GNCT of Delhi), Dilshad Garden, Delhi - 110095, India

Abstract

The patients presenting with metastasis to cervix are handful. Breast is one of the common extragenital site that can metastasize to cervix. Early diagnosis and treatment are the keys to right management. We hereby report an advanced case of breast cancer that was found to have an incidental synchronous lesion in cervix on a PET Scan. She showed limited response to systemic treatment. The overall survival was 8.5 months.

Keywords: Metastasis to cervix; Incidental; Synchronous; Breast cancer

Key-Messages

Breast cancer can metastasize to unusual sites. Infiltrating ductal carcinoma metastasizing to cervix is rare and few cases have been reported till now. A thorough gynecological examination is often recommended. Immunohistochemistry can differentiate between a primary and metastatic cervical lesion and should be done wherever feasible.

\section{Introduction}

Breast cancer is a renowned systemic disease that metastasizes by lymphatic and hematogenous routes although the preferable route of spread is lymphatic [1]. Breast cancer commonly metastasizes to bones, lungs, lymph nodes, liver, and brain $[2,3]$. Breast cancer metastasizing to cervix is rare. To the best of our knowledge, only 43 cases have been reported in literature till now [4-25]. In majority of patients, breast cancer precedes the diagnosis of metastasis. Of the total reported cases of cervical metastasis, only nine presented with a synchronous lesion in breast [24]. The histology that most often migrates to cervix is infiltrating lobular breast cancer (ILC) $[25,26]$. The case reported here highlights the importance of unusual site of metastasis of breast cancer; need for a thorough gynecological examination in a case of breast cancer; unusual presentation for an infiltrating ductal carcinoma (IDC); synchronous presentation of breast cancer with cervical metastasis and use of immunohistochemistry for diagnosis if possible.

\section{Case History}

A 45 years old married premenopausal female with two live children presented with a lump in left breast of three months duration. There was no past history of usage of oral contraceptive pills or hormones in her life. On local examination, she had a single $12 \times 10 \mathrm{~cm}$ hard lump in central quadrant of left breast free from overlying skin and underlying chest-wall with associated nipple retraction. Ipsilateral supraclavicular fossa was full. Contralateral breast, supraclavicular fossa and bilateral axillae appear normal. Bilateral breast mammography showed architectural distortion in upper and middle quadrants of left breast and lymph nodes in both axillae. Fine Needle Aspiration Cytology from lump proved it Duct Carcinoma. Trucut biopsy (Figures 1 \& 2) proved it Infiltrating Duct Carcinoma Grade III with lobular pattern of infiltration; DCIS, LVSI and focal necrosis present; MBR Score $3+3+2=8 / 9$. Ultrasound Whole Abdomen and Pelvis showed bulky cervix and enlarged pelvic lymph nodes. Chest X Ray (PA view) was normal. Whole body PET Scan showed active hypermetabolic lesions in upper inner and outer quadrants of left breast with bilateral axillary, left internal mammary, mediastinal and left supraclavicular lymph nodes. Another hyper-metabolic soft tissue mass in cervix with bilateral inguinal and pelvic lymph nodes was incidentally noted.

On gynecological examination, cervix was hard and irregular, left parametrium and fornix were thickened and shortened, 
bleeding was present. Uterus was anteverted, mobile and non-tender, uterocervical length $=4$ inches. Endometrial and endocervical curettage (Figures $3 \& 4$ ) proved it a carcinoma metastatic to the cervix. She was finally diagnosed as a case of Carcinoma Breast cT4cN1cM1 with Cervix Metastasis. She received six cycles of intravenous chemotherapy with Inj. Cyclophosphamide (1200 mg), Adriamycin (80 mg) and 5-Fluorouracil (1250 mg) based regimen every 22 days.

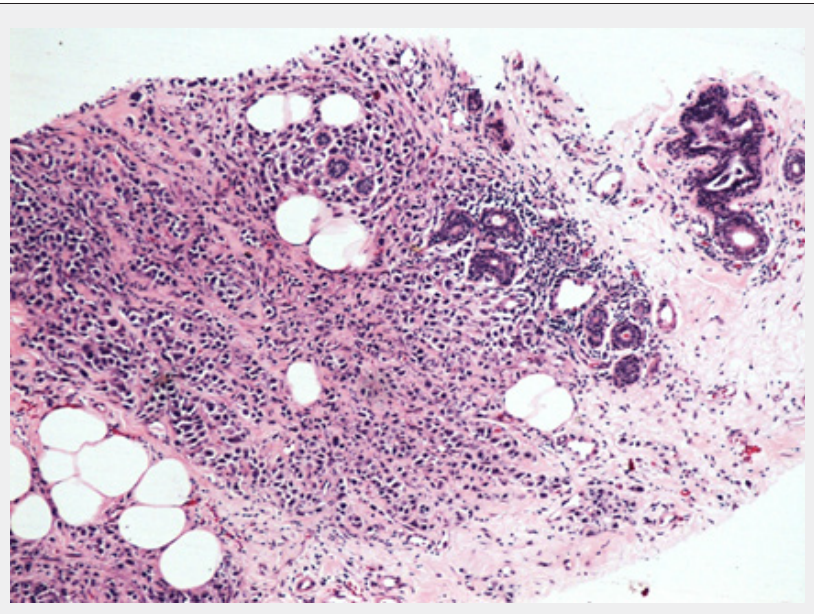

Figure 1: Trucut biopsy breast (10x) showing infiltrating duct carcinoma exhibiting lobular pattern (IDC-L).

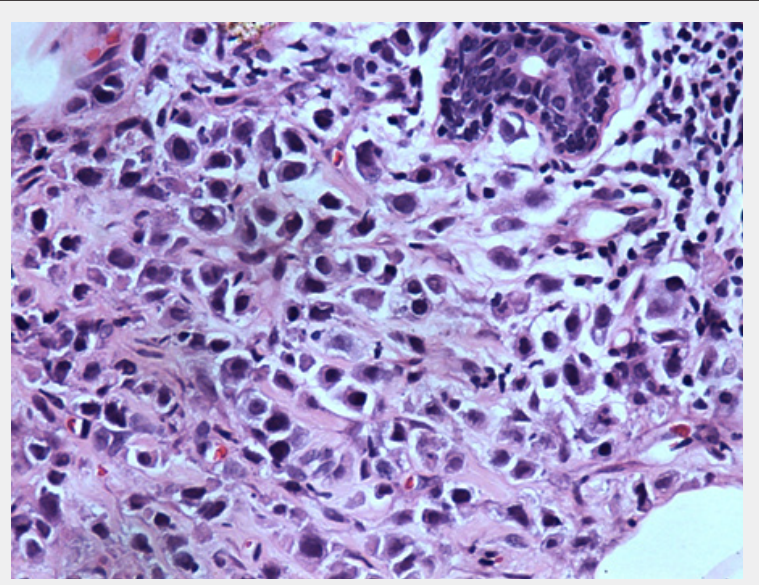

Figure 2: Trucut biopsy breast (40x) shows sheets of pleomorphic tumor cells with cohesive cellular arrangement along with lobular type of infiltration.

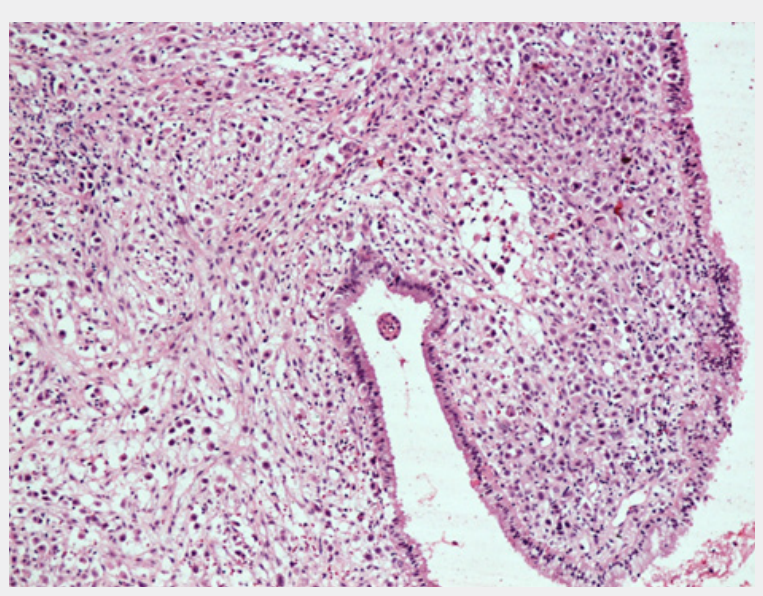

Figure 3: Cervix biopsy (10x) showing endocervical lining with subepithelial tumor infiltration. 


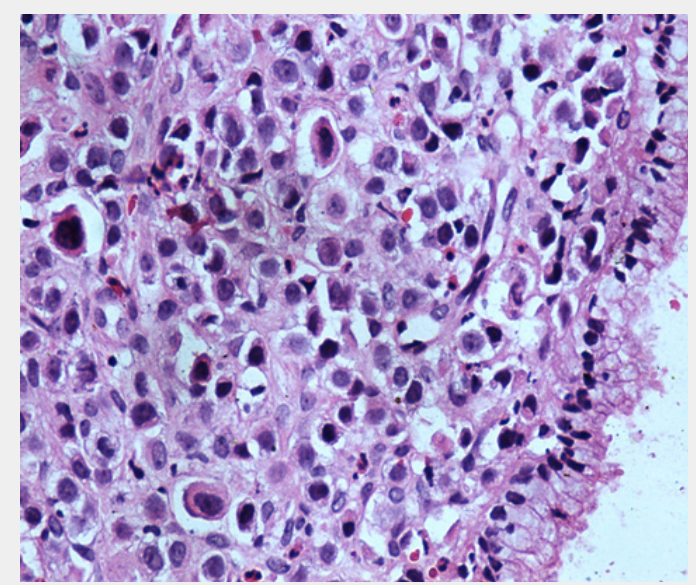

Figure 4: Cervix biopsy (40x) showing endocervical lining with subepithelial tumor infiltrates having similar morphology as of breast malignancy.

Whole Body PET scan done after chemotherapy showed a residual soft tissue density of $1.8 \times 1.5 \mathrm{~cm}$ size in upper inner quadrant of left breast. Cervical lesion, pelvic and inguinal lymph nodes were persistent with no significant response. She had disease progression with new lesions in various bones like manubrium sternum, right ilium, SI joint, body of D7, D8, D12, L1, L3 and L4 vertebrae. The patient was advised second line intravenous chemotherapy with Inj. Docetaxel (140 mg D1), Carboplatin (200 mg D1-D3), Ifosfamide (2 gm D1-D3) every 22 days. She did not turn up to hospital again and found to die a natural death on telephonic interrogation. The overall survival of patient was 8.5 months.

\section{Discussion}

Metastasis to cervix from extra-pelvic sites is rare as it is of small size, has less blood flow, distal circulation and abundant fibrous tissue [25]. In a review of 149 metastatic tumors to the female genital tract: the ovary, vagina and endometrium were the most frequent locations of metastases [27-29]. Only 3.4\% cases had metastases to cervix [29]. Extra-genital sites metastasizing to cervix include breast, stomach, lung, bowel, pancreas, bladder, liver, kidney and gallbladder [29]. A review by Lemoine et al found 33 cases with disease metastatic to cervix; four $(12 \%)$ of them were from a breast primary [12].

Gynecological examination is often not done in a case of breast cancer. Cervical lesions miss on routine clinical examination and it is less likely to be examined for metastases even during routine postmortem examination. The incidence is $0.3 \%$ in a review of 1000 autopsies [30]. In majority of cases, metastases are diagnosed later than primary although in some, presenting symptoms due to metastatic cervical tumor precede diagnosis of the primary tumor in the breast. The longest reported interval was 15 years between breast primary and cervix metastasis [21]. In the case reported here, the metastatic site was diagnosed incidentally with the primary disease in the same Whole-Body PET-CT Scan. Patient was although asymptomatic for this metastatic lesion in cervix. The suspicion raised by PET CT Scan got confirmed on gynecological examination. The presence of local bleeding was not a symptom and noticed only on gynecological examination. This case highlights the importance of thorough clinical examination of two sites. It simultaneously makes us think whether we should adopt gynecological examination as a routine when we examine a case of breast cancer and vice versa too.

Histological examination has its own importance in diagnosing cervix metastasis. Histologically, adenocarcinomas of cervix are rare in comparison to squamous cell carcinomas. Approximately $50 \%$ of them are secondary with their primary site of origin being breast [31,32]. ILC spreads more commonly to gynecological organs in comparison to IDC in the ratio 4:1 [25,26]. On a closer look, it was IDC exhibiting lobular pattern (IDC-L) metastasizing to cervix is being reported in this case. The patient was offered immunohistochemical (IHC) analysis (hormonal studies) as other patients but a clue to why it was not done was not available. The following markers may prove helpful in differentiating primary cervical lesion from metastasis: CK7/CK20, gross cystic disease fluid protein-15, p53, p16, vimentin, BCL2, p63, and napsin A [33].

As per evidence-based management and scientific logic, this patient should have received chemotherapy for her metastatic disease. She was offered palliative chemotherapy with CAF based regimen. Patient had good subjective response with partial reduction in the primary lesion. But the disease kept on progressing and involved multiple bones. She later succumbed and died a natural death at her home. Hence, we can conclude that cervix can be incidentally involved simultaneously in a case of breast cancer; thorough gynecological examination is useful in a case of breast cancer; early diagnosis and treatment are the 


\section{Cancer Therapy \& Oncology International Journal}

keys to right management. This case left us introspecting whether immunohistochemistry could have altered the course of disease and its management.

Taking positive cues, authors would recommend thorough gynecological examination in a case of carcinoma breast; breast examination in a case of carcinoma cervix and immunohistochemistry is mandatory if patient agrees for it. Screening for breast and cervical cancers could prove useful to the society where we are living. The limitation of the study is that the reporting authors were not the ones who encountered the patient on her first visit and subsequently. However, this case generated enough academic interest that later on proved a stimulus for its documentation as a case report. Further clinical information and radiology imaging could not be provided due to non-availability.

\section{Acknowledgement}

The authors wish to acknowledge the efforts of Dr Dhruv Jain and Dr Simarpreet Kaur in confirming pathological diagnosis.

\section{References}

1. Munazzah Rahman, Sulma Mohammed (2015) Breast cancer metastasis and the lymphatic system. Oncol Lett 10(3): 1233-1239.

2. Almagro E, González CS, Espinosa E (2016) Prognostic factors of early breast cancer. Med Clin (Barc) 146(4): 167-171.

3. Giestas S, Lopes S, Souto P, Agostinho C, Camacho E, et al. (2016) Ampullary metastasis from breast cancer: A rare cause of obstructive jaundice. GE Port J Gastroenterol 23(6): 300-303.

4. Way S (1980) Carcinoma metastatic in the cervix. Gynecol Oncol 9: 298-302.

5. Charache H (1941) Metastatic carcinoma in the uterus. Am J Surg 53: 152-157.

6. Cruz PT (1954) Mammary carcinoma with metastasis to the cervix uteri. Del Med J 26(12): 304-305.

7. Wallach JB, Edberg S (1959) Carcinoma metastatic to the uterine cervix. Am J Obstet Gynecol 77(5): 990-995.

8. Song J (1963) Metastatic carcinoma of the uterine cervix from primary breast cancer. JAMA 184: 498-500.

9. Korhonen M, Stenback F (1984) Adenocarcinoma metastatic to the uterine cervix. Gynecol Obstet Invest 17: 1757-65.

10. Cohan L, Kaplan AL (1984) Postmenopausal bleeding secondary to metastatic disease in the endocervix from carcinoma of the breast. Gynecol Oncol 17(1): 133-136.

11. Di Bonito L, Patriarca S, Alberico S (1985) Breast carcinoma metastasizing to the uterus. Eur J Gynaecol Oncol 6(3): 211-217.

12. Lemoine NR, Hall PA (1986) Epithelial tumors metastatic to the uterine cervix. A study of 33 cases and review of the literature. Cancer $57(10)$ : 2002-2005.

13. Giltrap S, Hall E, Newman M (1986) Metastatic breast carcinoma arising in the endometrium. Br J Obstet Gynaecol 93(5): 516-518.

14. Yazigi R, Sandstad J, Munoz AK (1988) Breast cancer metastasizing to the uterine cervix. Cancer 61(12): 2558-2560.
15. CA Bryson, RH de Courcy Wheeler, RJ Wallace (1999) Breast cancer metastasizing to the uterine cervix. Ulster Med J 68(1): 30-32.

16. Hepp HH, Hoos A, Leppien G, Wallwiener D (1999) Breast cancer metastatic to the uterine cervix: analysis of a rare event. Cancer Invest 17(7): 468-473.

17. Bogliolo S, Morotti M, Menada MV, Fulcheri E, Musizzano Y, et al (2010) Breast cancer with synchronous massive metastasis in the uterine cervix: a case report and review of the literature. Arch Gynecol Obstet 281(4): 769-773.

18. D'souza MM, Sharma RS, Tripathi M, Saw SK, Anad A, et al. (2010) Cervical and uterine metastasis from carcinoma of breast diagnosed by PET/CT. An unusual presentation. Clin Nucl Med 35(10): 820-823.

19. Horikawa M, Mori Y, Nagai S, Tanaka S, Saito S, et al. (2012) Metastatic breast cancer to the uterine cervix mimicking a giant cervical leiomyoma. Nagoya J Med Sci 74(3-4): 347-351.

20. Benkerroum Z, Babahabib A, Kouach J, Chahdi H, Al Bouzidi A, et al. (2014) Metrorrhagia disclosing a synchronous bilateral breast cancer: Report of a case. Gynecol Obstet Fertil 42(5): 360-364.

21. Waks AG, Lennon J, Yadav BS, Hwang H, dSchapirael Carmen M, et al. (2015) Metastasis to the cervix uteri 15 years after treatment of lobular carcinoma of the breast. Semin Oncol 42(4): e81-94.

22. Lokadasan R, Ratheesan K, Sukumaran R, Nair SP (2015) Metastatic lobular carcinoma of breast mimics primary cervix carcinoma: Two case reports and a review of the literature. Ecancermedicalscience 9: 571.

23. Proença S, Reis MI, Cominho J, Conde PC, Santos E Pereira H, et al. (2016) Metastatic breast cancer in uterine cervix: A rare presentation. Low Genit Tract Dis 20(1): e 1-3.

24. Sultana Razia, Kentaro Nakayama, Mayu Tsukao, Kohei Nakamura, Masako Ishikawa, et al. (2017) Metastasis of breast cancer to an endometrial polyp, the cervix and a leiomyoma: A case report and review of the literature. Oncol Lett 14(4): 4585-4592.

25. Silva Fontinele DR, Vieira SC, da Silva Júnior RG, Rodrigues TS (2019) Lobular carcinoma of the breast with metastasis to the uterine cervix. J Can Res Ther 15(6): 1411-1414.

26. Harris M, A Howell, M Chrissohou, R I Swindell, M Hudson, et al (1984) A comparison of the metastatic pattern of infiltrating lobular carcinoma and infiltrating duct carcinoma of the breast, $\mathrm{Br} \mathrm{J}$ Cancer 50(1): 23-30.

27. Lamovec J, Bracko M (1991) Metastatic pattern of infiltrating lobular carcinoma of the breast: an autopsy study. J Surg Oncol 48(1): 28-33.

28. Pomerance W, Mackles A (1962) Adenocarcinoma of the cervix. Am J Obstet Gynecol 84: 367- 374

29. Mazur MT, Hsueh S, Gersell DJ (1984) Metastases to the female genital tract: analysis of 325 cases. Cancer 53(9): 1978-1984.

30. Abrams HL, Spiro R, Goldstein N (1950) Metastases in carcinoma; Analysis of 1000 autopsied cases. Cancer 3(1): 74-85.

31. Abell MR, Cosling JGR (1962) Gland cell carcinoma (adenocarcinoma) of the uterine cervix, Am J Obstet Gynecol 83: 729-755.

32. PérezMontiel D, SerranoOlvera A, Salazar LC, CetinaPérez L, Candelaria M, et al. (2012) Adenocarcinoma metastatic to the uterine cervix: A case series. J Obstet Gynaecol Res 38(3): 541549.

33. Merino D, Lok SW, Visvader JE, Lindeman GJ (2016) Targeting BCL-2 to enhance vulnerability to therapy in estrogen receptor-positive breast cancer. Oncogene 35(15): 1877-1887. 
Your next submission with Juniper Publishers will reach you the below assets

- Quality Editorial service

- Swift Peer Review

- Reprints availability

- E-prints Service

- Manuscript Podcast for convenient understanding

- Global attainment for your research

- Manuscript accessibility in different formats ( Pdf, E-pub, Full Text, Audio)

- Unceasing customer service

Track the below URL for one-step submission https://juniperpublishers.com/online-submission.php 